\title{
Assessment and management of patients with chronic cough by Certified Respiratory Educators: A randomized controlled trial
}

\author{
Stephen K Field MD CM FRCPC, Diane P Conley RRT CRE, Amin M Thawer RRT CRE, \\ Richard Leigh MD PhD FRCPC, Robert L Cowie MD MSc FCPSA
}

SK Field, DP Conley, AM Thawer, R Leigh, RL Cowie. Assessment and management of patients with chronic cough by Certified Respiratory Educators: A randomized controlled trial. Can Respir J 2009;16(2):49-54.

BACKGROUND: The value of other health care professionals is increasingly being recognized to compensate for the shortage of physicians in Canada. Chronic cough is one of the most common reasons for consultation with a respirologist. In the present study, a prospective, randomized, controlled study was undertaken to determine whether Certified Respiratory Educators (CREs) could manage screened patients with chronic cough as effectively as respirologists. METHODS: An eight-week, prospective, parallel-design, randomized, controlled trial of the management of chronic cough patients was conducted. Patients were screened to exclude those with potentially life-threatening conditions. The primary outcome was the number of patients whose cough resolved or subjectively improved.

RESULTS: A total of 198 patients were randomly assigned, and eightweek data were available on 151 patients. Mean age of the patients was $49.8 \pm 13.4$ years, $70.2 \%$ were female and median cough duration was 16 months. The screening process was effective and referral wait times decreased from a median of two months to less than four weeks $(\mathrm{P}<0.0001)$. The educators averaged 4.9 contacts per patient compared with 2.7 by the physicians over the eight-week study period $(\mathrm{P}<0.0001)$. Most patients had had multiple therapeutic trials before referral. Cough resolved or improved in two-thirds of the patients at eight weeks; however, more patients showed improvement in the educator arm than in the physician arm, $\mathrm{P}<0.02$. Cough-specific quality of life improved similarly in the two study arms at eight weeks (physician arm: $61.5 \pm 14.1$ to $52.6 \pm 14.4, \mathrm{P}<0.0001$; CRE arm: $58.1 \pm 14.9$ to $50.0 \pm 15.8, \mathrm{P}=0.0003)$.

CONCLUSIONS: CREs can safely and effectively assess, as well as appropriately treat, screened patients with chronic cough with a resultant reduction in wait times.

Key Words: Asthma; Certified respiratory educator; Chronic cough; Gastroesophageal reflux; Outcome measures; Rhinitis; Wait times

Canada has one of the lowest physician to population ratios among the Organisation for Economic Co-operation and Development countries (1). Access to medical services, including specialist care, is an increasingly challenging problem in Canada (2). The most practical and expedient option to deal with the physician shortage has been the greater use of nurse practitioners and other health professionals to furnish services previously provided by physicians.
Examen et prise en charge de patients souffrant de toux chronique par des moniteurs certifiés en pneumologie : Étude randomisée et contrôlée

HISTORIQUE : On reconnaît de plus en plus le rôle que d'autres professions de la santé sont appelées à jouer pour pallier la pénurie de médecins au Canada. La toux chronique est l'un des motifs de consultation les plus fréquents en pneumologie. La présente étude prospective, randomisée et contrôlée visait à déterminer si des moniteurs certifiés en pneumologie (MCP) pouvaient assurer aussi efficacement que les pneumologues la prise en charge de certains patients sélectionnés souffrant de toux chronique.

MÉTHODES : Les auteurs ont donc procédé à une étude prospective, randomisée et contrôlée avec groupes parallèles d'une durée de huit semaines sur la prise en charge des patients atteints de toux chronique. La sélection des patients avait pour but d'exclure ceux qui souffraient de maladie à potentiel fatal. Le principal paramètre était le nombre de patients dont la toux était rentrée dans l'ordre ou s'était subjectivement améliorée.

RÉSULTATS : En tout, 198 patients ont été randomisés et des données ont été recueillies sur 151 patients pour la période de huit semaines. L'âge moyen des patients était de 49,8 \pm 13,4 ans, 70,2 \% étaient des femmes et la durée médiane de la toux était de 16 mois. Le processus de sélection a été efficace et les temps d'attente pour consultation sont passés d'une durée médiane de deux mois à moins de quatre semaines $(\mathrm{p}<0,0001)$. En moyenne, les moniteurs ont eu 4,9 rencontres par patient, comparativement à 2,7 pour les médecins au cours de la période de huit semaines de l'étude $(\mathrm{p}<0,0001)$. La plupart des patients avaient essayé plusieurs traitements avant la consultation. La toux était rentrée dans l'ordre ou s'était améliorée chez les deux tiers des patients à la semaine 8. Toutefois, l'état de santé s'était amélioré chez un plus grand nombre de patients vus par les moniteurs plutôt que par les médecins $(\mathrm{p}<0,02)$. La qualité de vie liée à la toux avait connu une amélioration similaire dans les deux groupes de l'étude à la semaine 8 (groupe vu par les médecins $61,5 \pm 14,1$ à $52,6 \pm 14,4$, $\mathrm{p}<0,0001$; groupe MCP, $58,1 \pm 14,9$ à 50,0 $\pm 15,8, \mathrm{p}=0,0003$ ).

CONCLUSIONS : Les MCP peuvent examiner et traiter de manière sécuritaire, efficace et appropriée les patients sélectionnés présentant une toux chronique, permettant ainsi de réduire les temps d'attente.

In Canada, respiratory educator programs have been developed for health professionals, including nurses, respiratory therapists, physiotherapists and pharmacists (3). Certified Respiratory Educators (CREs) supply services traditionally delivered by physicians, such as patient education with an emphasis on patient self-management, instruction in proper inhaler technique, advice to patients about their asthma or chronic obstructive pulmonary disease, and provision of details 
for dealing with exacerbations (3). They are also trained to counsel patients regarding smoking cessation techniques and to perform basic spirometry. Potential advantages in the use of CREs include their specific training and experience in patient education, reduced wait times, more time for physicians to see more urgent patients, and cost savings by the use of less expensive personnel.

Chronic cough is the most common symptomatic complaint in the outpatient setting and one of the most common reasons for consultation with a respiratory medicine specialist, accounting for up to $38 \%$ of their outpatient referrals (4-6). Patients with an abnormal chest radiograph, hemoptysis, a history of cancer or lung disease, other significant comorbidities such as congestive heart failure, or systemic symptoms require a complete evaluation by a physician to determine whether they have a life-threatening disease. However, in the absence of sinister features, patients are likely to have one or a combination of asthma, an upper airway condition or gastroesophageal reflux responsible for their cough; conditions that CREs have been trained to recognize as part of the differential diagnosis of asthma (3,7-10). Other common causes include postinfectious cough, cigarette smoking, medication-induced cough (most commonly due to an angiotensin-converting enzyme inhibitor) and laryngeal irritation (8).

The assessment and management of patients with chronic cough and a normal chest radiograph is usually straightforward. In most patients, a complete medical history, physical examination and spirometry will suggest the cause or causes (7). Moreover, empirical treatment of chronic cough based on this approach is cost-effective (11). We reasoned that the respirologist workload and wait times might improve if CREs were able to assess and manage patients with chronic cough who do not have chest radiograph abnormalities or sinister symptoms. We therefore undertook a comparative study of the management of patients with chronic cough, screened to exclude those with sinister features, to determine whether CREs would be as effective as respirologists in achieving resolution or subjective improvement of the patient's chronic cough.

\section{METHODS}

The present study was an eight-week, prospective, randomized, parallel-group clinical trial. Blinding of the patients was not feasible. The protocol was approved by the Conjoint University of Calgary/Calgary Health Region (Calgary, Alberta) bioethics office. The primary objective was to determine whether the cough resolved, improved or did not improve over an eightweek follow-up period. Secondary objectives included patient safety (ie, to determine whether the screening process failed to identify patients with potentially life-threatening conditions) and the impact of the program on wait times for patients with chronic cough.

\section{Inclusion criteria}

All subjects had a chest radiograph performed within two months of the first clinic visit. Patients with minor abnormalities, such as a small calcified nodule, were included if the principal investigator believed that it was appropriate after personally reviewing the chest $\mathrm{x}$-ray. Several patients were reported to have chest radiographs demonstrating hyperinflation; however, they were included if their spirometry was normal. All subjects were 18 years of age or older, had experienced cough for a minimum of four weeks, did not have any of the exclusion criteria and were willing to give written, informed consent.

\section{Exclusion criteria}

Patients referred for evaluation of chronic cough were screened to exclude those with abnormal chest radiographs, hemoptysis, dyspnea, a history of cancer or serious lung disease, serious comorbid conditions, or systemic symptoms such as involuntary weight loss of $5 \mathrm{~kg}$ or more, lassitude, malaise or extreme fatigue that could not be explained by sleep disruption due to their cough, fever, night sweats or chills. Patients with a condition known to cause immunodeficiency were excluded.

Patients were also excluded if they had other investigations suggesting a serious underlying illness, including blood tests suggesting a serious abnormality, abnormal computed tomography scan even if the routine chest $\mathrm{x}$-ray was reported to be normal, or abnormal sputum cytology. Pregnancy was a reason for exclusion because it might influence investigation and treatment decisions. Patients who did not have an adequate command of English to complete the questionnaire, or patients who were unable to return for follow-up visits were also excluded.

\section{Protocol}

One of the educators screened the cough clinic referrals to ensure that the patients did not have any of the exclusion criteria. Referral letters, pulmonary function reports and chest radiograph reports were reviewed to determine whether any exclusion criteria were present. Before random assignment, patients were specifically questioned to ensure that they met inclusion criteria and did not have any exclusion criteria. Unless they had undergone pulmonary function testing within four weeks, all subjects had spirometry at their initial visit. Spirometry was performed according to American Thoracic Society standards. Forced expiratory volume in $1 \mathrm{~s}\left(\mathrm{FEV}_{1}\right)$, forced vital capacity (FVC) and $\mathrm{FEV}_{1} / \mathrm{FVC}$ ratio were recorded. Knudsen references including adjustments for age, sex, height and weight were used. Values were also corrected for race. Patients with an $\mathrm{FEV}_{1} / \mathrm{FVC}$ less than 0.7 or an $\mathrm{FEV}_{1}$ less than $80 \%$ of the predicted value were retested $10 \mathrm{~min}$ after inhaling $400 \mu \mathrm{g}$ of salbutamol. All subjects completed a validated cough-specific quality of life (CSQL) questionnaire before random assignment and at the end of the study period eight weeks later (12). At eight weeks, patients were asked whether their cough was still present and if present, whether it had improved. They were also asked about the presence and severity of their cough-associated symptoms. A computer program was used to randomly assign patients to the educator or physician arm. Their allocation to the physician or CRE arm was determined by opening the next of 400 sequentially numbered sealed envelopes. Random assignment was achieved by using two equal lists of random numbers, one for each limb of the study. These two lists were then combined in a database and indexed in ascending order. The study number allocated to each random number and recorded on the sealed envelope was the random number's rank in the indexed list. This process provided approximately equal numbers in each treatment limb and an unpredictable sequence of allocation. No adjustment of allocation could be made after the subject had been enrolled. 
For those patients randomly assigned to the physician group, the participating respirologists were at liberty to order any investigations or treatments that they believed were appropriate. They could choose to see patients only once or as often as they believed was appropriate. Patients were seen by the same physician at their follow-up visits.

Patients in both arms were assessed with a formal questionnaire designed to identify the possible causes of their chronic cough. They were asked about the nature and timing of their cough, and about possible triggers - such as cigarette smoke exposure, exposure to animals or other common allergens and situations or manoeuvres that relieved their cough. They were asked about previous specialist referrals, investigations and therapeutic trials.

The educators had an additional form to guide them through the history (including family, medical and surgical history), occupation and physical examination of the patients. The form also provided a list of relevant medications, medication allergies or intolerances, and an area to record their diagnosis or diagnoses, investigation and treatment plans. The physical examination included vital signs, measurement of height and weight, visual assessment of the upper airway, palpation of the neck and auscultation of the chest, as well as examination of the cardiovascular system, visual inspection for jugular venous distension and checking for peripheral edema. Some patients were also skin tested for six locally common aeroallergens. The CREs discussed and explained the differential diagnosis of chronic cough and the rationale for each of the therapeutic interventions. If appropriate, they instructed the patients in the proper use of an inhaler. Presently, CREs are not allowed to order investigations or prescribe medication. However, they recorded their diagnostic impressions and recommendations for investigations and management before review with the physician, who was responsible for prescribing.

The CREs had several therapeutic options (13). Depending on their clinical impression, they chose options from one or more of the streams in the clinical algorithm outlined in Figure 1:

- Smokers were counselled about smoking cessation using standard smoking cessation materials with a particular emphasis on the relationship between their chronic cough and smoking. Educators could recommend over-the-counter nicotine replacement. They could also request a prescription for varenicline tartrate (Champix [Pfizer, Canada]) for their patient from a physician.

- Patients could be switched from an angiotensin-converting enzyme inhibitor to an angiotensin receptor blocker if the blood pressure was reasonably controlled (systolic blood pressure less than $150 \mathrm{mmHg}$ and diastolic blood pressure less than $90 \mathrm{mmHg}$ ). If the antihypertensive medication was changed, the patient was instructed to have a blood pressure check within two weeks.

- The CREs could recommend several therapeutic options for suspected postinfectious cough including reassurance, a nasal saline spray, antihistamine alone or in combination with a decongestant, or ipratropium bromide aqueous nasal spray.

- A nonprescription nasal saline spray or saline rinses, allergen avoidance, oral antihistamines and/or a corticosteroid nasal spray could be prescribed if the clinical presentation was

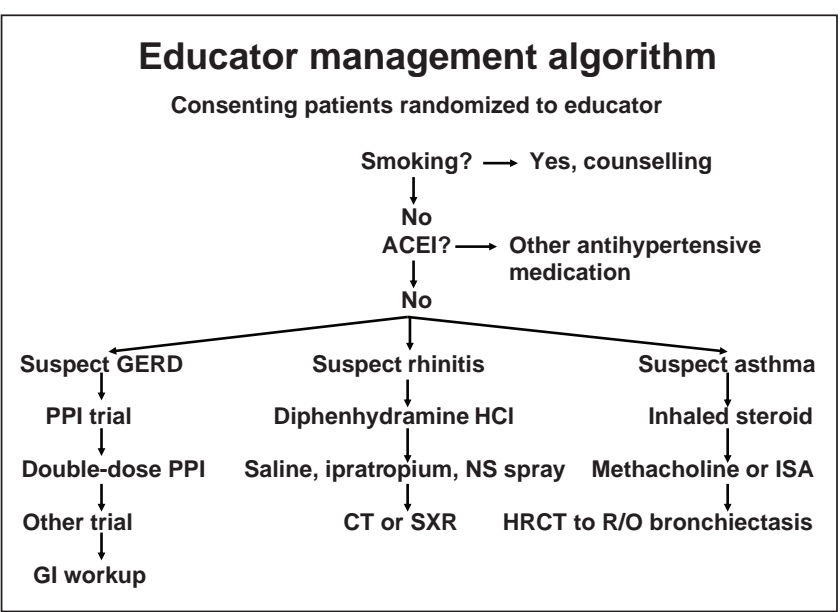

Figure 1) Treatment algorithm used by the certified respiratory educators. ACEI Angiotensin-converting enzyme inhibitor; CT Computed tomography; GERD Gastroesophageal reflux disease; GI Gastrointestinal; HCl Hydrochloride; HRCT High-resolution computed tomography; ISA Induced sputum analysis; NS Nasal steroid; PPI Proton pump inhibitor; R/O Rule out; SXR Sinus x-ray

suggestive of allergic rhinitis. Skin testing to common aeroallergens, including cat and dog dander, mould, dust mite, and local grass and tree pollens, to confirm the diagnosis of atopy was also an option. The CREs also had the option of an oral antihistamine, with or without decongestant, or nasal ipratropium bromide aqueous spray for suspected vasomotor rhinitis.

- Patients with symptoms suggesting asthma, or spirometry indicating airway obstruction, were prescribed an inhaled corticosteroid.

- Patients with symptoms of gastroesophageal reflux were advised about lifestyle changes, and could be prescribed omeprazole (14).

The CREs contacted patients by telephone at two and at six weeks, and the patients attended the cough clinic at four and at eight weeks for reassessment and adjustment of their treatment. If patients in the educator arm did not improve after eight weeks, they could be referred to one of the respirologists in an open fashion.

Although the study could not be blinded for logistical reasons, physicians and research staff were unaware of the treatment allocation before random assignment. Although blinding was not feasible, the patients only had a general knowledge of the objectives of the study.

\section{Statistics}

Data were collected on all of the study patients. Data that were normally distributed are presented as the mean \pm SD. Differences between normally distributed data of the two groups were compared using the student's $t$ test. Data not normally distributed are expressed as medians and were analyzed using the MannWhitney $\mathrm{U}$ test. Categorical and ordinal patient outcomes, such as cough resolution, improved or not improved cough, and cough-associated symptoms were compared using McNemar's test, $\chi^{2}$ test or Fisher's exact test. For all statistical analyses, $\mathrm{P}<0.05$ was considered to be statistically significant. 
TABLE 1

Patient demographics ( $n=151)$

\begin{tabular}{|c|c|c|c|}
\hline Demographics & Respirologist & Educator & $\mathbf{P}$ \\
\hline Number of patients, $n$ & 78 & 73 & - \\
\hline Age, years, mean \pm SD & $46.1 \pm 12.7$ & $53.6 \pm 13.1$ & 0.0005 \\
\hline Female/male & $54 / 24$ & $52 / 21$ & NS \\
\hline $\mathrm{BMI}, \mathrm{kg} / \mathrm{m}^{2}$, mean $\pm \mathrm{SD}$ & $27.8 \pm 5.6$ & $28.3 \pm 6.5$ & NS \\
\hline Smokers, $\mathrm{n}$ & 4 & 4 & NS \\
\hline Former smokers, $\mathrm{n}$ & 12 & 22 & 0.01 \\
\hline $\mathrm{FEV}_{1}, \mathrm{~L}$, mean $\pm \mathrm{SD}$ & $2.9 \pm 0.8$ & $2.9 \pm 0.9$ & NS \\
\hline $\begin{array}{l}\text { Cough duration, months, } \\
\text { median (range) }\end{array}$ & $16(1-840)$ & $15(2-360)$ & NS \\
\hline
\end{tabular}

BMI Body mass index; FEV 1 Forced expiratory volume in $1 \mathrm{~s}$; NS Not significant

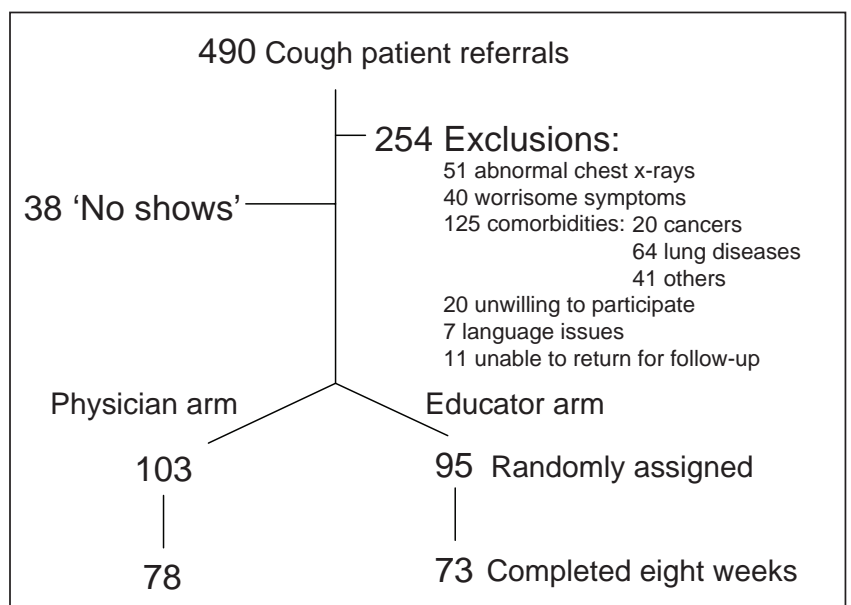

Figure 2) Patient disposition. A total of 490 patients were referred. Thirty-eight never showed for a scheduled appointment. Some patients were given three separate appointments but never came to the clinic. A total of 254 patients were excluded from the study for various reasons. A total of 198 patients were randomly assigned, and eight-week data were available on 151 patients

\section{Sample size}

The calculations for sample size were based on the results of CSQL in the report by French et al (12). A difference of $10 \%$ or less between the two arms of the study was considered to not be clinically significant. To demonstrate that the results of the patients in the CRE arm were $10 \%$ poorer than in the physician-treated arm, with a two-armed test with an alpha of 0.05 and a desired power of 0.80 , required 57 patients in each $\operatorname{arm}(15)$.

\section{RESULTS}

A total of 198 patients were randomly assigned, and eight-week data were available on 151 patients. Table 1 presents the patient demographics, and patient disposition is outlined in Figure 2. Cough was present for a median of 16 months in referred patients. The mean age of the patients was $49.8 \pm 13.4$ years, and similar to other reports, the majority of patients were female, reflecting the high prevalence and concerns due to coughrelated stress incontinence. There were only eight current smokers among the study subjects. Therapeutic trials and specialist evaluations before referral to the cough clinic are outlined in Figure 3 and Figure 4, respectively.

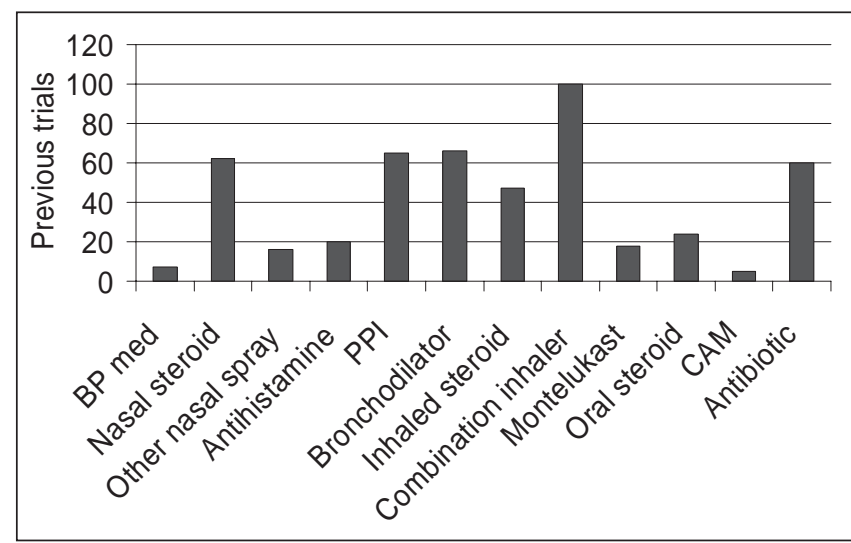

Figure 3) Number of therapeutic trials before patients $(n=198)$ were referred to the cough clinic. BP med Blood pressure medication; CAM Complementary or alternative medicine; PPI Proton pump inhibitor

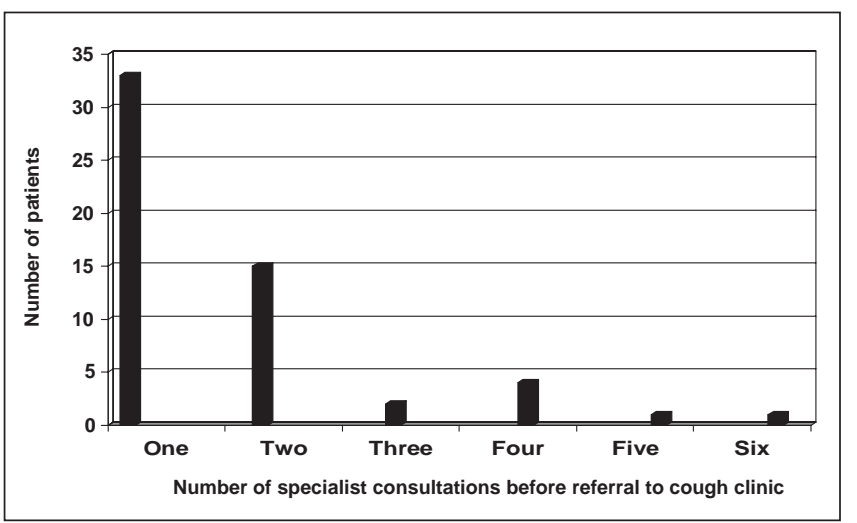

Figure 4) Number of consultants seen before patients were referred to the clinic. Approximately one-third of the patients were seen by at least one specialist before referral to the cough clinic. Some patients saw more than one consultant in the same specialty. Fifty-six patients had 96 previous consultations. Patients had seen 29 ear, nose and throat, 20 pulmonary, 12 allergy, 12 gastrointestinal and five other specialists

\section{Safety}

Only five of the 490 referred patients (1\%) were inappropriately entered into the study. Despite having normal chest radiographs, four patients were subsequently diagnosed with bronchiectasis and one with interstitial lung disease. Two patients with bronchiectasis were randomly assigned to the educator. Despite having normal chest radiographs, one had unilateral crackles and high-resolution computed tomography revealed bronchiectasis. Another patient, randomly assigned to the physician arm, had an FVC in the low normal range and bibasilar crackles, which led to further testing that confirmed the presence of interstitial disease.

\section{Effect on wait times}

The availability of CREs to see the chronic cough patients reduced wait times from a median of two months to less than four weeks $(\mathrm{P}<0.0001)$. Moreover, reducing the number of chronic cough patients on the respirologist clinic list expedited the assessment of the other patients on the wait lists with more serious conditions. 
Outcomes at eight weeks

The educators had an average of 4.9 contacts (patient visit or telephone call) with their patients, and the physicians averaged 2.7 contacts per patient over the eight-week period $(\mathrm{P}<0.0001)$. Cough resolved in $37 \%$ of the CRE arm patients and in $22 \%$ of the respirologist arm patients. Cough improved but had not completely disappeared in 35\% of the CRE patients and $33 \%$ of the respirologist patients. At eight weeks, cough did not improve in $29 \%$ and $45 \%$ of the educator and physician patients, respectively, $\mathrm{P}<0.02$.

Cough-associated symptoms and anxiety improved in both groups (Figure 5). The prevalence of cough-associated retching at eight weeks decreased from $48 \%$ to $27 \%, \mathrm{P}=0.0002$, and from $61 \%$ to $40 \%, \mathrm{P}=0.0003$, in the $\mathrm{CRE}$ and respirologist arms, respectively. The prevalence of stress incontinence in women decreased from $46 \%$ to $33 \%, \mathrm{P}=0.05$, and from $44 \%$ to $32 \%, \mathrm{P}=0.03$, in the $\mathrm{CRE}$ and respirologist arms, respectively. The reduction in the proportion of patients with sleep disruption (CRE arm, $45 \%$ to $36 \%$; physician arm: $42 \%$ to $36 \%$ ) was not statistically significant. Patient concerns about a serious underlying condition decreased from $45 \%$ to $22 \%, \mathrm{P}<0.0001$, and from $60 \%$ to $38 \%, \mathrm{P}=0.001$, in the $\mathrm{CRE}$ and respirologist arms, respectively. The differences between the changes in the two arms at eight weeks were not statistically significant. CSQL improved in the two study arms at eight weeks (physician arm: $61.5 \pm 14.1$ to $52.6 \pm 14.4, \mathrm{P}<0.0001$; CRE arm: $58.1 \pm 14.9$ to $50.0 \pm 15.8, P=0.0003)$. CSQL was the same in the two groups at the beginning $(\mathrm{P}=0.26)$ and at eight weeks $(\mathrm{P}=0.42)$.

\section{DISCUSSION}

The current study demonstrates that CREs can safely and effectively assess and manage appropriately screened patients with chronic cough. Outcomes, including rates of cough improvement and resolution, and improvements in cough-related symptoms (such as retching, stress incontinence, and patient concerns and anxiety about having a serious underlying condition) were significantly improved after eight weeks. Advantages of using CREs are that they can assess the patients and modify empirical treatments more frequently than physicians, have more time to discuss the patient's symptoms and concerns, and are there to reassure the patient about the benign nature of the cough. More available time for counselling and reassurance are especially important to help patients to emotionally deal with a condition that may not have a clear-cut diagnosis and requires an empirical approach to treatment. It should also improve patient compliance, increasing the likelihood of successful treatment. Moreover, the use of CREs halved patient wait times.

Improvements in total CSQL were similar in the two arms of the study. The cough resolution and improvement rates were better in the educator arm, likely because the patients in the educator arm were contacted more frequently during the eightweek period, and there were more opportunities to modify therapy. Cough outcomes in our study were not as good as others reported previously $(5,7,16)$. Other investigators have assessed outcomes after three or four months, allowing more time for improvement. Successful responses to treatment may take considerably longer than eight weeks (5). Our follow-up assessment was made at eight weeks for ethical reasons. Because patients were waiting two months or longer to be seen by a respirologist before the study, we believed it would be ethical

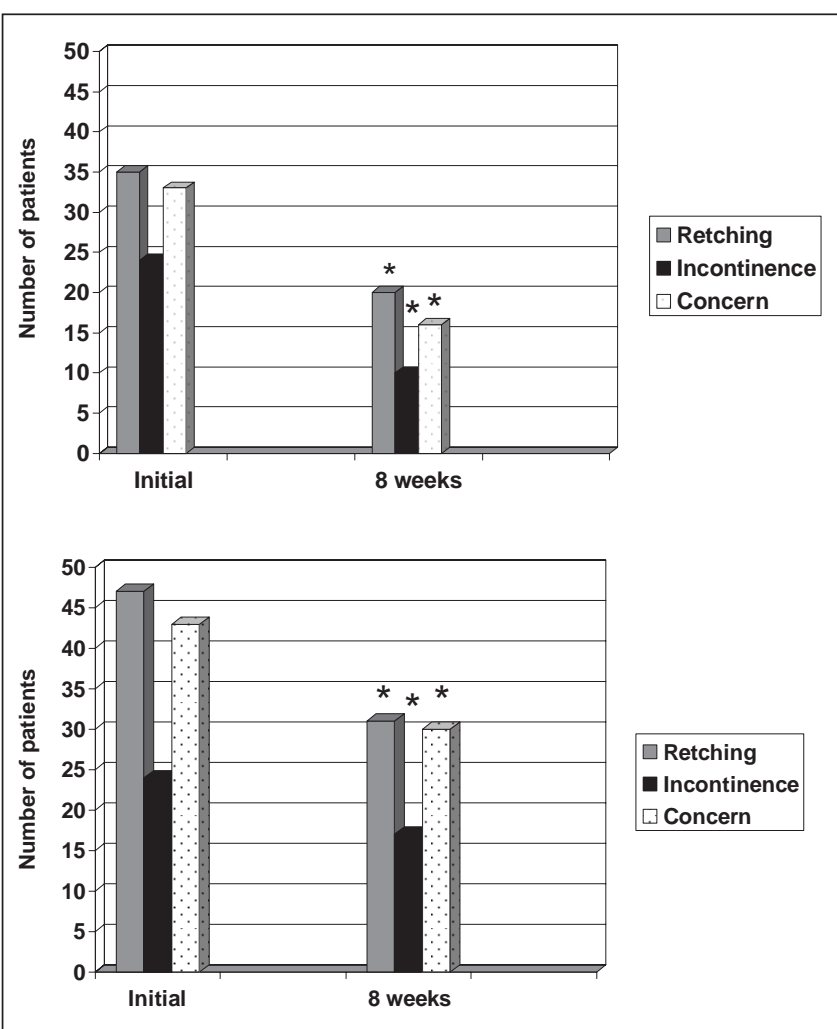

Figure 5) Prevalences of cough-associated retching, stress incontinence (women only) and patient concern that their cough represents a serious underlying condition, initially and at eight weeks. Top Educator patient data. Bottom Respirologist patient data. $* P<0.05$

for the patient to be seen by the educator in the time window between referral and two months, the normal time that they would require to be seen by a consultant. Had the outcomes in the educator arm been inferior, they would still be seen as quickly by a respirologist had they not entered the study.

Over the past three decades, primary care physicians have developed a better understanding of the causes and management of chronic cough. Patients who fail treatment in the primary care setting and require referral for chronic cough have become more complex and are more likely to have multiple causes contributing to their chronic cough (5). Most patients in the current study underwent a number of investigations and multiple therapeutic trials, and 28\% had seen at least one consultant previously for assessment and management of their chronic cough. The success rate of our highly selected referrals, who failed empirical trials in the primary care setting, would be expected to be more modest than a cohort not already subjected to multiple treatment trials.

Approximately one-half of the patients referred for assessment and management of chronic cough had normal chest radiographs, and lacked symptoms or underlying health conditions that would preclude management by a CRE. Our screening protocol effectively excluded patients with sinister underlying conditions. Only five of 198 randomly assigned patients had an underlying condition (bronchiectasis in four patients and interstitial lung disease in one) that should have been exclusions. None of the patients have been subsequently diagnosed with a serious chronic infection or lung cancer. 
The insistence of the provincial college of physicians and surgeons, the professional licensing agency, the local government health authority, and the national professional medical liability organization, on physician involvement in the care of all patients required a modification of the initial study design. A physician briefly met each of the educator patients and was ultimately responsible for prescribing investigations and treatment for the educator patients. This was achieved with minimal patient contact, essentially to approve the educators' recommendations, order diagnostic tests and to provide prescriptions, and was unlikely to have influenced the perceptions or outcomes of the patients.

We were unable to obtain eight-week CSQL data on approximately one-quarter of the patients in each group, despite making every effort to retain all of the patients in the study. Patients who did not complete the questionnaire were contacted by telephone three times and were sent several mailouts of the CSQL questionnaire with self-addressed envelopes.

The demographics of our patients were similar to other published chronic cough cohorts (16-19). Our patients were predominantly middle-aged women who had cough for a median of 16 months. The female predominance in these studies is largely driven by the high prevalence of stress incontinence and the greater impact of chronic cough on quality of life in women $(17,18)$. In the absence of radiographic abnormalities, or other respiratory or systemic symptoms, virtually all patients

\section{REFERENCES}

1. Kondro W. Canada's physician density remains stagnant. CMAJ 2006;175:465.

2. Canadian Institute for Health Information. Supply, distribution and migration of Canadian physicians 2005. < http://secure.cihi.ca/ cihiweb/dispPage.jsp?cw_page $=$ PG_587_E\&cw_topic $=587 \& \mathrm{cw}$ rel=AR_14_E\#full > (Version current at January 23, 2009).

3. Cicutto L, Burns P, Brown N. A training program for certified asthma educators: Assessing performance. J Asthma 2005;42:561-5.

4. Schappert SM, Burt CW. Ambulatory care visits to physician offices, hospital outpatient departments, and emergency departments: United States 2001-02. Vital Health Stat 13 2006:1-66.

5. Irwin RS, Curley FJ, French CL. Chronic cough: The spectrum and frequency of causes, key components of diagnostic evaluation, and outcome of specific therapy. Am Rev Respir Dis 1990;141:641-7.

6. French CT, Irwin RS, Curley FJ, Krikorian CJ. Impact of chronic cough on quality of life. Arch Intern Med 1998;158:1657-61.

7. Irwin RS, Corrao WM, Pratter MR. Chronic persistent cough in the adult: The spectrum and frequency of causes and successful outcome of specific therapy. Am Rev Respir Dis 1981;123:413-7.

8. Pratter MR. Overview of common causes of chronic cough. ACCP evidence-based clinical practice guidelines. Chest 2006;129:59S-62S.

9. Irwin RS, Madison JM. The persistently troublesome cough. Am J Respir Crit Care Med 2002;165:1469-74.

10. Harding SM. Chronic cough. Practical considerations. Chest 2003; 123:659-60.

11. Lin L, Poh KL, Lim TK. Empirical treatment of chronic cough. A cost-effectiveness analysis. Proc AMIA Symp 2001:383-7.

12. French CT, Irwin RS, Fletcher KE, Adams TM. Evaluation of a cough-specific quality-of-life questionnaire. Chest 2002;121:1123-31. have a benign cause for their cough; usually an upper airway cause, mild asthma, gastroesophageal reflux or a combination of these $(5,7)$. However, the associated symptoms, such as retching, incontinence, sleep disruption or syncope, may be disabling and cause absences from work or school, which may lead to job loss and limited academic achievement, respectively (19). Regardless of the underlying diagnosis, chronic cough frequently causes anxiety and depression (20-22). Despite the profound impact on their lifestyles, these patients are often a low priority for respirologists and experience long wait times because serious underlying illness is unusual. The present study demonstrates that CREs have the necessary knowledge and, with a minimum of clinical examination instruction, the skills to properly assess and recommend treatment for these patients. The inclusion of chronic cough to their mandate of asthma, chronic obstructive pulmonary disease and smoking cessation is a logical strategy to help deal with the physician shortage in Canada.

Presented at the American Thoracic Society International Conference in May 2008.

ACKNOWLEDGEMENTS: The authors are grateful for innovation funding from the Calgary Health Region Department of Medicine for salary support, and sincerely thank Dr Richard Irwin and his colleagues at the University of Massachusetts for permission to use their cough-specific quality-of-life questionnaire.
13. Irwin RS, Baumann MH, Bolser DC, et al. Diagnosis and management of cough executive summary. ACCP evidence-based clinical practice guidelines. Chest 2006;129:1S-23S.

14. Chang AB, Lasserson TJ, Kiljander TO, Connor FL, Gaffney JT, Garske LA. Systemic review and meta-analysis of randomized controlled trials of gastro-oesophageal reflux interventions for chronic cough associated with gastro-oesophageal reflux. BMJ 2006;332:11-7.

15. Web based sample size/power calculations. $<$ http://www.stat.ubc.ca/ $\sim$ rollin/stats/ssize/index.html $>$ (Version current at January 23, 2009).

16. Hoffstein V. Persistent cough in nonsmokers. Can Respir J 1994;1:40-7.

17. French CT, Fletcher KE, Irwin RS. Gender differences in healthrelated quality of life in patients complaining of chronic cough. Chest 2004;125:482-8.

18. French CT, Fletcher KE, Irwin RS. A comparison of gender differences in health-related quality of life in acute and chronic coughers. Chest 2005;127:1991-8.

19. Everett CF, Kastelik JA, Thompson RH, Morice AH. Chronic persistent cough in the community: A questionnaire survey. Cough 2007;3:5.

20. Dicpinigaitis PV, Tso R, Banauch G. Prevalence of depressive symptoms among patients with chronic ocugh. Chest 2006;130:1839-43.

21. McGarvey LPA, Carton C, Gamble LA, et al. Prevalence of psychomorbidity among patients with chronic cough. Cough 2006;2:4.

22. Kuzniar TJ, Morgenthaler TI, Afessa B, Lim KG. Chronic cough from the patient's perspective. Mayo Clin Proc 2007;82:56-60. 


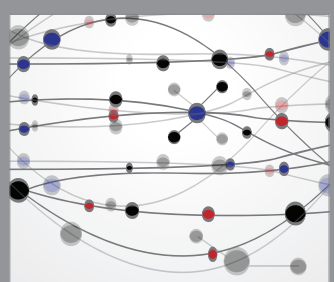

The Scientific World Journal
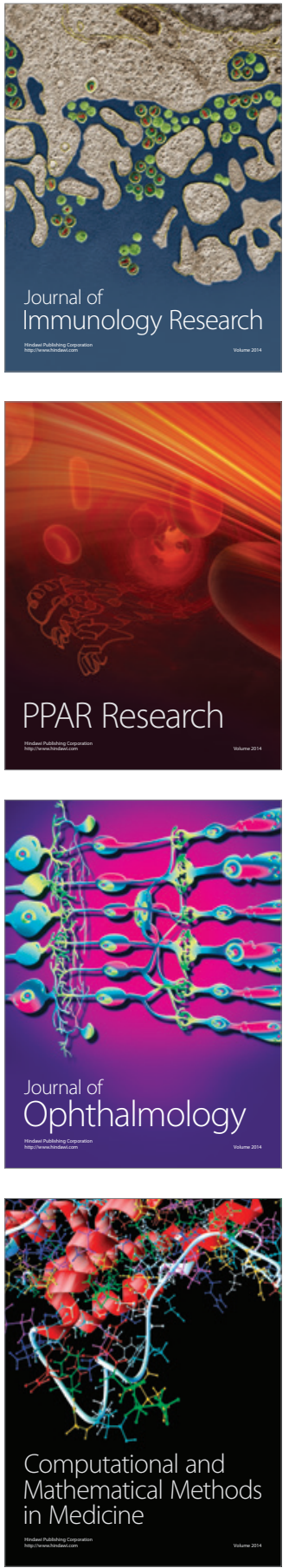

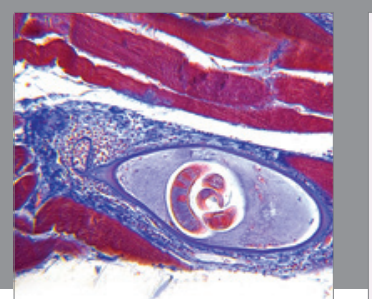

Gastroenterology Research and Practice

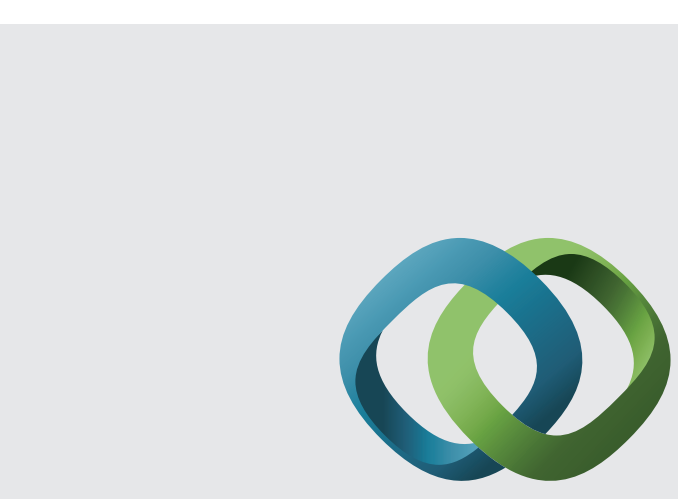

\section{Hindawi}

Submit your manuscripts at

http://www.hindawi.com
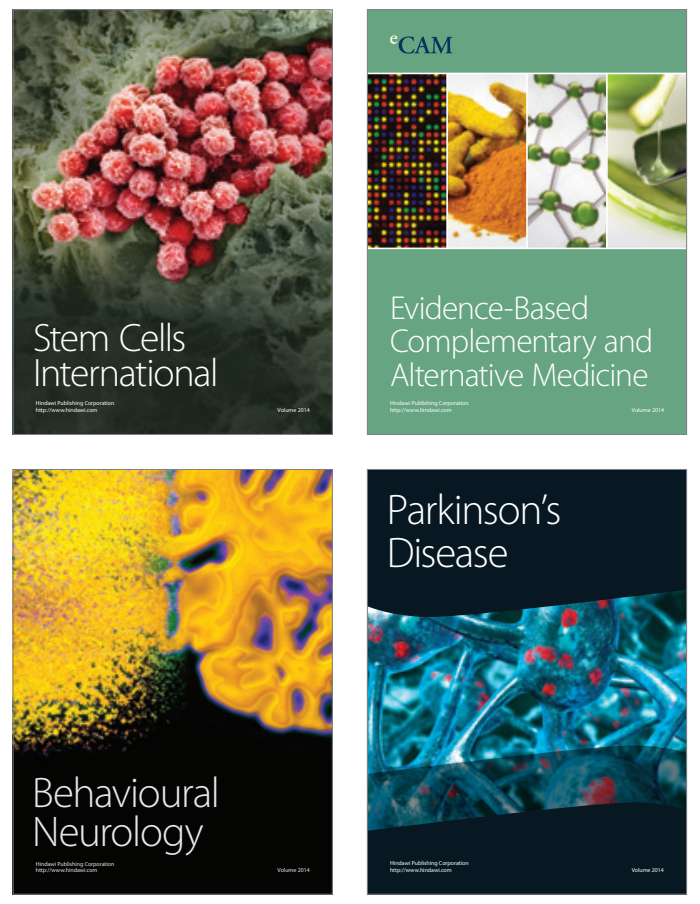
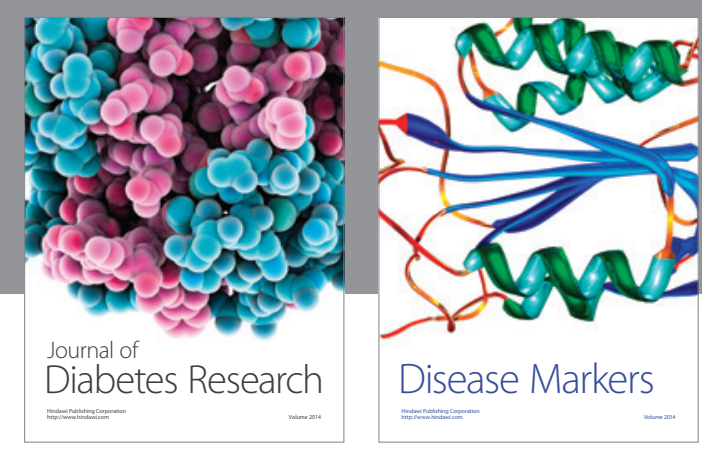

Disease Markers
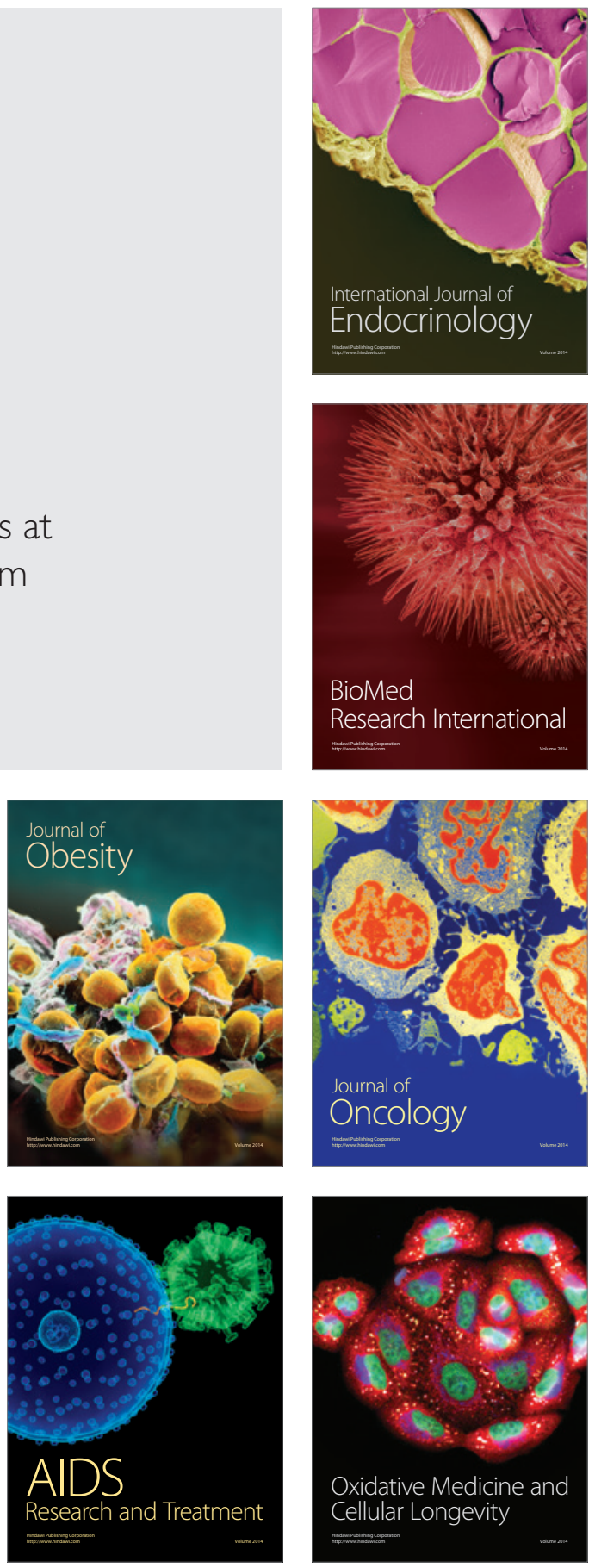